\title{
Anaphylaxis in children and adolescents: the Portuguese Anaphylaxis Registry
}

\author{
Angela Gaspar ${ }^{1}$, Natacha Santos ${ }^{2}$, Emilia Faria ${ }^{3}$, Ana Pereira ${ }^{4}$, Eva Gomez ${ }^{5}$, Rita \\ Câmara $^{6}$, Rodrigo Rodrigues-Alves ${ }^{7}$, Luìs Miguel Borrego ${ }^{8}$, Isabel Carrapatoso ${ }^{3}$, Leonor \\ Carneiro-Leão ${ }^{9}$, Mário Morais-Almeida ${ }^{10}$, Luís Delgado ${ }^{11}$, Elisa Pedro ${ }^{12}$, and Manuel \\ Branco-Ferreira ${ }^{12}$ \\ ${ }^{1}$ Hospital da Luz Lisboa \\ ${ }^{2}$ Centro Hospitalar Universitário Algarve \\ ${ }^{3}$ Centro Hospitalar e Universitário de Coimbra EPE \\ ${ }^{4}$ Hospital CUF Porto and Instituto CUF Porto \\ ${ }^{5}$ Centro Hospitalar Universitário do Porto EPE \\ ${ }^{6}$ Centro Hospitalar do Funchal \\ ${ }^{7}$ Hospital do Divino Espírito Santo de Ponta Delgada EPE \\ ${ }^{8}$ Universidade Nova de Lisboa Faculdade de Ciências Médicas \\ ${ }^{9}$ Centro Hospitalar de São João EPE \\ ${ }^{10}$ Hospital CUF Descobertas \\ ${ }^{11}$ University of Porto Faculty of Medicine \\ ${ }^{12}$ Hospital de Santa Maria
}

September 16, 2020

\begin{abstract}
Background: Anaphylaxis is increasing at pediatric age; however, its characterization is hampered by underdiagnosis and underreporting. The aim of this study was to identify the causes of anaphylaxis in children and adolescents in Portugal, thus contributing to a better knowledge of its etiology, clinical manifestations and management. Methods: During a 10-year period a nationwide notification system for anaphylaxis was implemented, with voluntary reporting by allergists. Data on 533 patients under 18 years of age with anaphylaxis were included. Results: Mean age was $8.5 \pm 4.9$ years, $61 \%$ were male; $45 \%$ had asthma. Mean age at the first anaphylaxis episode was $5.3 \pm 4.7$ years (ranging from 1 month to 17 years of age), $63 \%$ at preschool age. Most reactions occurred at home (57\%). Food-induced anaphylaxis was the leading cause (77\%). The main culprit foods were cow's milk (32\%), tree nuts (16\%), shellfish (13\%), egg (12\%), fresh fruits (11\%), fish (8\%) and peanut (8\%). Other causes included drugs (11\%), insect-sting (5\%), cold-induced anaphylaxis (4\%), exercise-induced ( $2 \%)$, latex (1\%) and idiopathic anaphylaxis (1\%). Most patients (83\%) were admitted to the emergency department; only $46 \%$ received adrenaline treatment. Recurrence of anaphylaxis occurred in $41 \%$ of the patients ( 3 or more episodes in $21 \%$ ). An adrenaline autoinjector was used in $9 \%$ of the patients. Conclusions: In the Portuguese pediatric population, food is the leading cause of anaphylaxis. Undertreatment with adrenaline and high recurrence of anaphylaxis highlight the need to improve both the diagnosis and the therapeutic management of this life-threatening entity.
\end{abstract}

\section{Hosted file}

Article - Anaphylaxis children 10-year SPAIC.docx available at https://authorea.com/ users/359609/articles/481472-anaphylaxis-in-children-and-adolescents-the-portuguese- 
anaphylaxis-registry

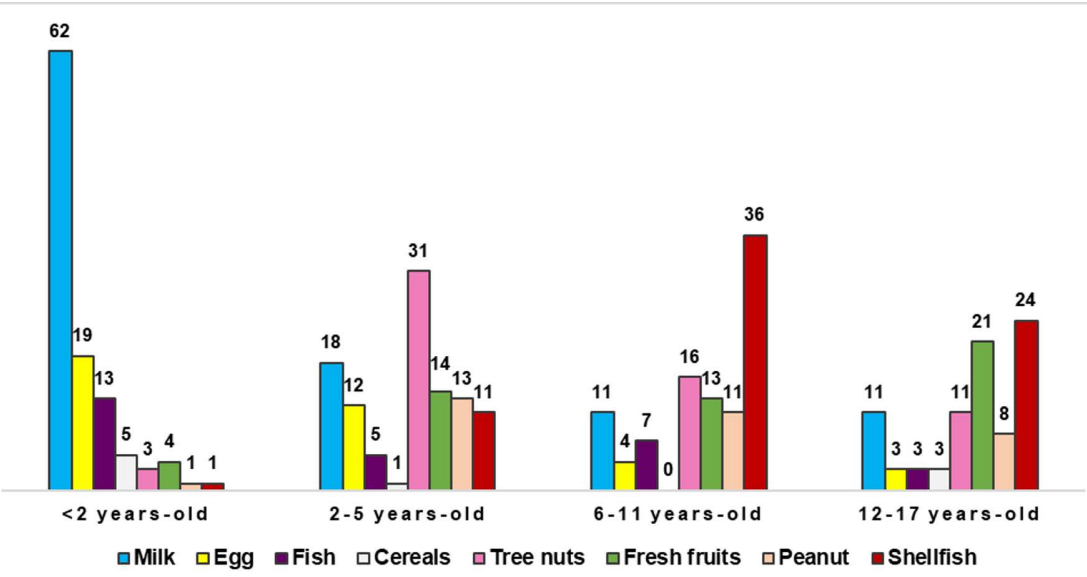

